\title{
DYSPNEA AND NECK PAIN 4 DAYS AFTER A FALL - SHOULD WE HURRY?
} A CASE REPORT

Authors: Costa-Martins, I.; Mer, S.; Nascimento, A.; Gordillo, I.; André, A.I.

Institute: Centro Hospitalar de Lisboa Ocidental, E.P.E.

\section{BACKGROUND}

Cervical trauma can be associated with C-spine injury and the airway may be compromised by disruption, edema or hematoma. It can cause life threatening airway obstruction, but sometimes the clinical onset may be delayed for days.

\section{CASE REPORT}

Patient
- Male, 77 years old, ASA III
- History of ankylosing spondylitis, hypertension,
CPOD, on antiplatelet therapy.

\section{HISTORY}

- Admitted on emergency department due to neck pain 4 days after a fall from his own height

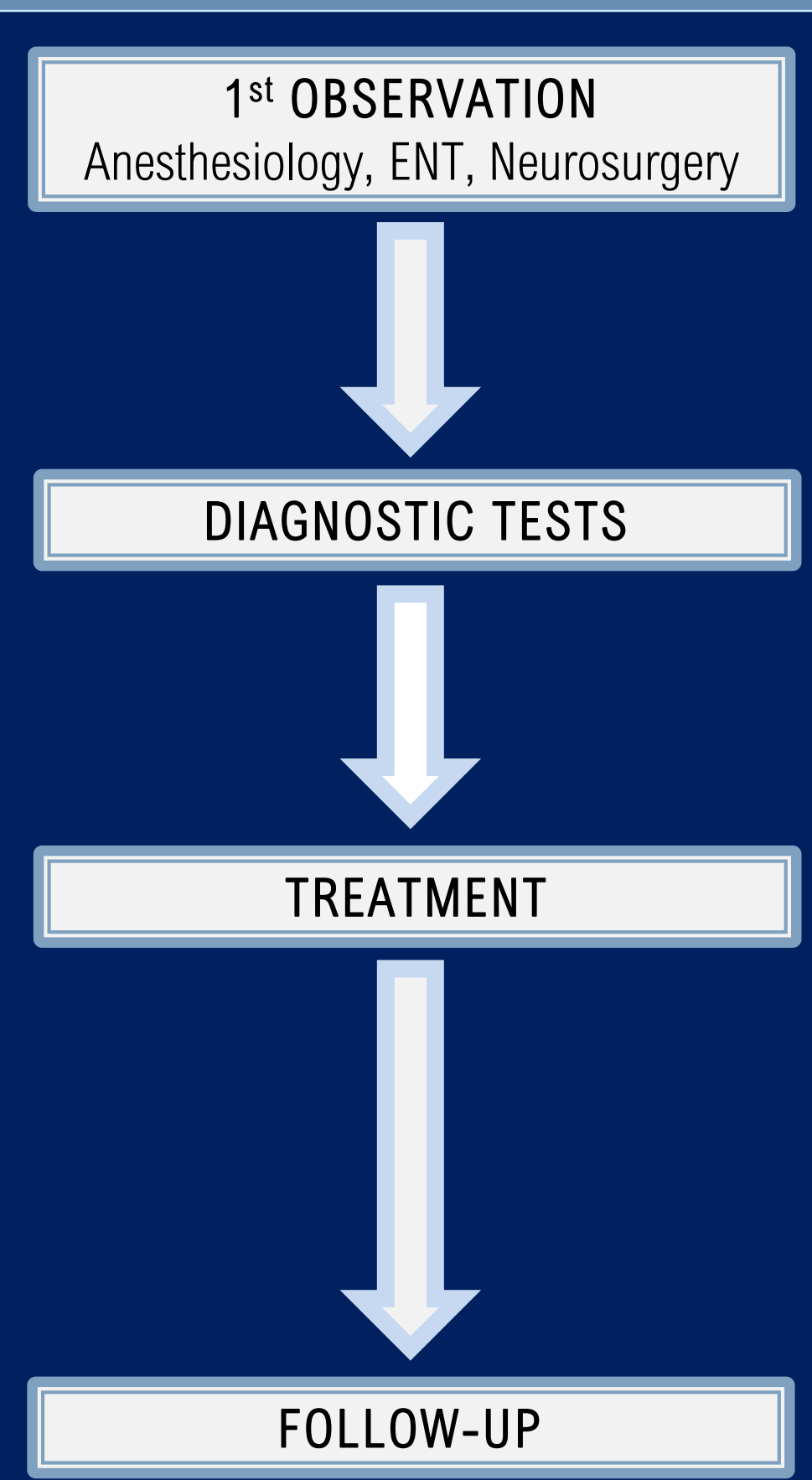

- Conscient, oriented, with a GCS 15

- Respiratory distress, dysphonia and dysphagia

- Cervical collar, limited mouth opening, Mallampati IV and exuberant cervical and periorbital hematomas (figure 1).

- Cervical CT scan revealed a C4 fracture and a C3 to C6 prevertebral soft tissue mass compressing the airway (figure 2).

- Urgent tracheotomy under monitored anesthesia care, with spontaneous breathing and bimanual in-line stabilization of cervical spine. Subsequent videolaryngoscopy showed an extremely narrowed supraglottic opening.

- 3 days later a posterior C2-C6 cervical fixation was performed.

- The patient stayed in the ICU under ventilatory support for hematoma's reabsorption, then transferred to the neurosurgical ward

- 2 months since admission he was discharged with a reestablished airway and respiratory functions and mild neurologic deficits.

- At 1 year reevaluation there were no complications.

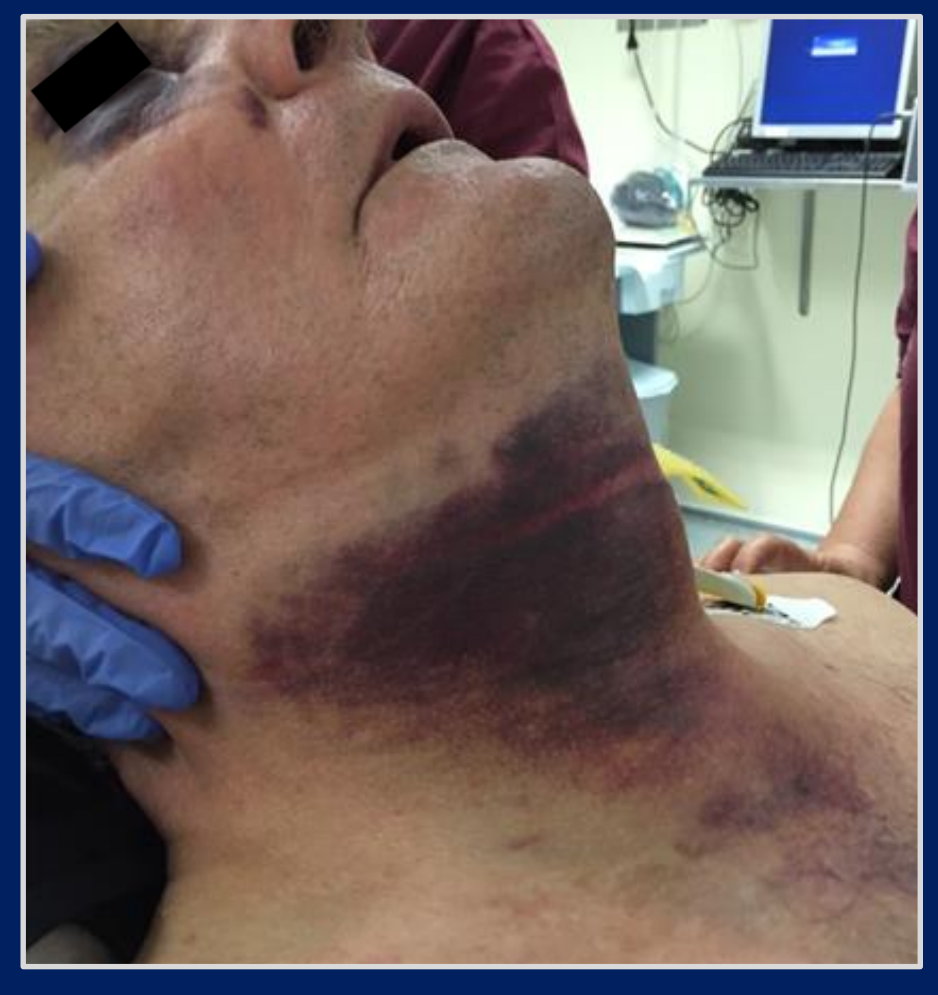

Figure 1 - Cervical and periorbital hematomas

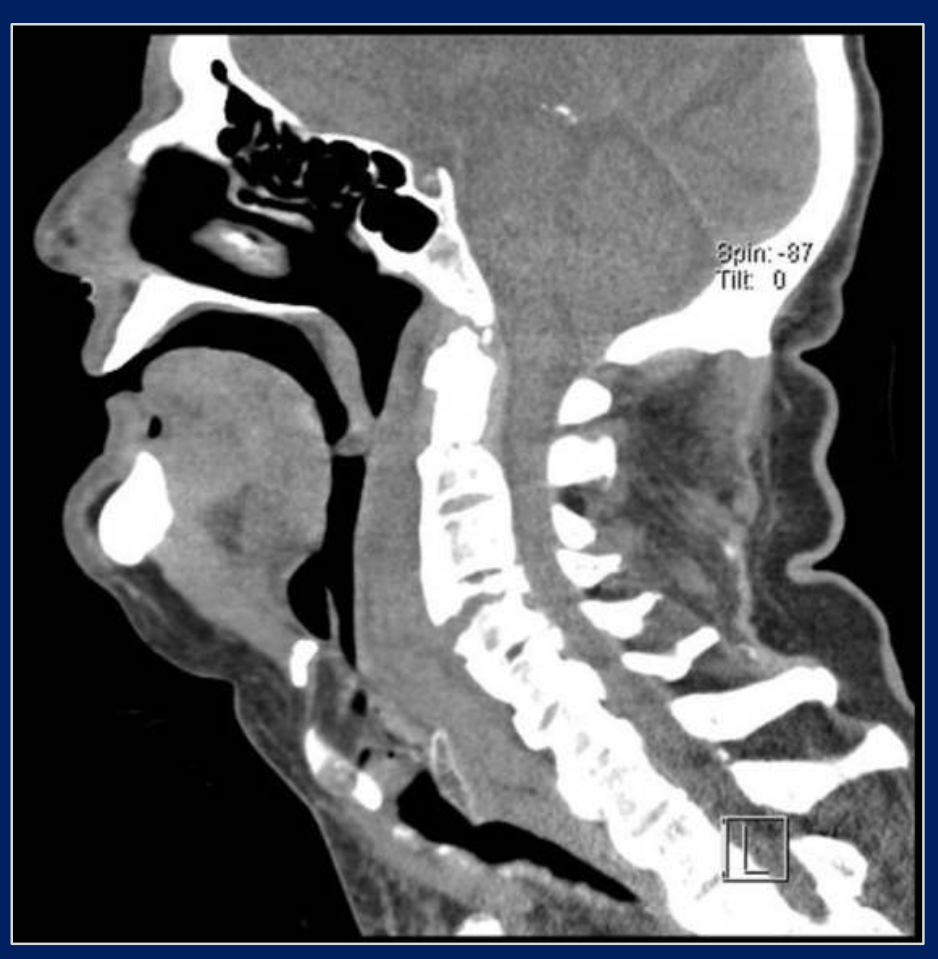

Figure 2 - Cervical CT scan

\section{DISCUSSION}

Retropharyngeal space hemorrhage is commonly associated with blunt cervical trauma and anticoagulant therapy and can cause airway obstruction(2).

The choice between primary surgical airway, awake intubation, rapid sequence induction and watchful waiting without intubation is a clinical decision that depends on patient's condition, material and human resources ${ }^{(1)}$.

Awake fiberoptic intubation is usually the first strategy however without the anesthesiologist expertise and with suspected severe glottic stenosis the risk of hematoma's dislodgement was too high(2). In teamwork we decided surgical airway was the best approach.

\section{LEARNING POINTS}
1. Cervical hematoma may rapidly progress to lethal airway obstruction.
3. One must be aware of associated spinal injuries.
2. The first step is establishing definitive airway control.
4. A multidisciplinary approach privileging patient's security is the key to success

\section{REFERENCES}

1. Levy J. Management of the Traumatized Airway. Anesthesiology. 2016 Jan; 124

2. Lazzot $L$ et al. Severe upper airway obstruction due to delayed retropharyngeal hematoma formation following blunt cervical trauma. BMC Anesthesiology. 2007; 7 